\title{
Synthesis and immobilisation of 2-aminoimidazole derivatives on the organosilanised surface of Ti6Al4V alloy.
}

María J. Arévalo Caballero, ${ }^{\mathrm{a}, *}$ Ignacio M. López-Coca, ${ }^{\mathrm{a}}$ David G. Piedrahita, ${ }^{\mathrm{a}}$ Guadalupe Silvero.

${ }^{a}$ Labasoc, Escuela Politécnica, Departamento de Química Orgánica e Inorgánica, Universidad de Extremadura, Cáceres 10003, SPAIN

${ }^{b}$ Labasoc, Facultad de Veterinaria, Departamento de Química Orgánica e Inorgánica, Universidad de Extremadura, Cáceres 10003, SPAIN

arevalo@unex.es

Abstract: The Ti6Al4V alloy is widely used in biomedical devices because of its superior mechanical properties and its biocompatibility with the physiological system. The infections in biomaterials implanted in live beings are normally associated with the formation of a biofilm that is difficult to eradicate, resulting in serious health problems and increasing costs. Functionalisation of biomaterials with organic molecules with antibacterial capacity is currently studied as a strategy to improve their performance and safety after implantation. This paper reports the method for the immobilisation of a 2-aminoimidazole structure on Ti6Al4V surface. Firstly we describe the synthesis of 2-aminoamidazole according to a previously reported and efficient methodology; it is based on the reaction of 2-aminopyrimidines and $\alpha$-bromocarbonyl compounds, followed by the cleavage of an intermediate salt with hydrazine. Then the modification of the Ti6Al4V alloy surface was accomplished in two steps. First, the surface was silanised with two different alcoxysilanes: 3-aminopropyltrimethoxysilane or 3methacryloxypropyl-trimethoxysilane, in order to provide the surface with two different functional groups. Organosilane presence on the surface was verified by XPS and the amine groups density of the aminosilanised Ti6Al4V was quantified by a ninhydrin assay. After that, the 2-aminoimidazole was immobilised on the alloy surface, as confirmed by XPS.

Keywords: 2-aminoimidazole, Ti6Al4V, surface functionalisation, silanisation, immobilisation

\section{Introduction}

In recent years the development of new and more sophisticated biomaterials have led to the production of different types of implants and prostheses that effectively replace injured or malfunctioning body parts. As a result, there has been an increasing use of these dental, cardiovascular and synthetic substitutes.

The Ti6Al4V alloy has been widely investigated as an implant biomaterial because of its strength, high density and resistance to corrosion processes, as well as a good osseointegration capability.

However, due to its high surface roughness, the alloy is prone to adhesion of both Gramnegative and Gram-positive bacteria, such as $P$. aeruginosa and $S$. aureus, respectively. Bacterial adhesion on the surface of titanium-based medical devices begins with the formation of weak Van der Waals bonds. (Rautray et al., 2010) If these pathogens are not promptly removed, they begin to excrete a glue-like substance that anchors them more firmly, and accumulation of new bacteria in this scaffold, called biofilm, occurs. Biofilms are formed by a 
complex polymeric matrix that protects the pathogens from antibiotics. Hence, once the infection has taken place and the biofilm is formed, it is very difficult to eradicate. These events may ultimately lead to implant failure and the need for its removal, with a high social and economic cost associated. (Ando et al., 2010)

In order to mitigate the proliferation of bacterial biofilms functionalisation and anchoring of bactericidal compounds on the biomaterial have been reported. (Ang et al., 2016)

Some 2-aminoimidazoles, isolated from marine sponges of the genus Leucetta, show antibiotic activity against various pathogenic bacteria (Mai, T. et al. 2015; Žula et al., 2015). In previous studies, it has been observed that 2-aminoimidazole derivatives bearing halide atoms in positions 4 and 5 inhibit by $90 \%$ the formation of bacterial biofilms of $S$. aureus (Fung et al., 2014).

With all this in mind, we have reasoned that a chloro-substituted aminoimidazol would represent an interesting molecule to be anchored on the biomaterial surface, and that it might confer the alloy some antibacterial protection. The synthesis of 2-aminoimidazoles can be accomplished by means of different procedures; some of the most commons methods are (a) reaction of cyanamide with $\alpha$-aminoketone (Baran et al., 2004); (b) condensation of a guanidine derivative with $\alpha$-haloketone (Papeo et al., 2005); and (c) reaction of 2-aminopirimidine with $\alpha$ bromoketone (Ermolat'ev et al., 2011).

In this study, we wanted to check whether anchoring 2-amino-4-(4-chlorophenyl) imidazole to the surface of Ti6Al4V alloy could be effectively achieved.

For this purpose, the target 2-aminoimidazole molecule was synthesised and put in contact with the alloy surface, which had been previously modified by passivation and silanisation; finally, $\mathrm{X}$-ray photoelectron spectroscopy was used for the characterisation of the coated material.

\section{Results and discussion}

\subsection{Synthesis of the target molecule}

In this work we planned the synthesis of structures of 1,4-disubstituted-2-aminoimidazole by means of a two-step process. In the first step, the cyclocondensation of 2-aminopyrimidine with $\alpha$-bromocarbonyl compounds yields an immidazole[1,2-a]pyrimidinium salt as intermediate product. This salt, in the second step, is reacted with excess hydrazine to yield substituted 2aminoimidazoles (Ermolat'ev et al., 2006). Effectively, the reaction of 2-bromo-1-(4chlorophenyl)ethanone (1) with 2-aminopyrimidine (2) in refluxing acetonitrile formed the fluorescent 2-(4-chlorophenyl)- $1 H$-imidazo[1,2-a]pyrimidin-4-ylium bromide (3), as shown in Scheme 2. The same reaction proceeded at room temperature, as well; in both cases, yields were similar (65-70\%).

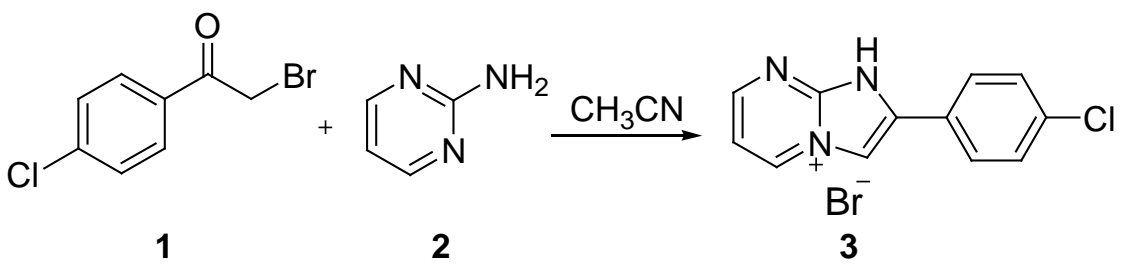


Scheme 2. Synthesis of 2-(4-chlorophenyl)-1H-imidazo[1,2-a]pyrimidin-4-ylium bromide.

The transformation of the intermediate salt into the final product 4-(4-chlorophenyl)-4,5dihydro- $1 \mathrm{H}$-imidazol-2-amine (5) was achieved by means of addition of excess hydrazine hydrate (4) to 3 in refluxing ethanol. After 5 hours the product was obtained in $52 \%$ yield. The same reactions was be carried out by microwave activation, at $120^{\circ} \mathrm{C}$ in a sealed vial, in just 40 min, with a slightly lower yield (42\%). (Scheme 3). This transformation is believed to occur by a Dimroth-type rearrangement.

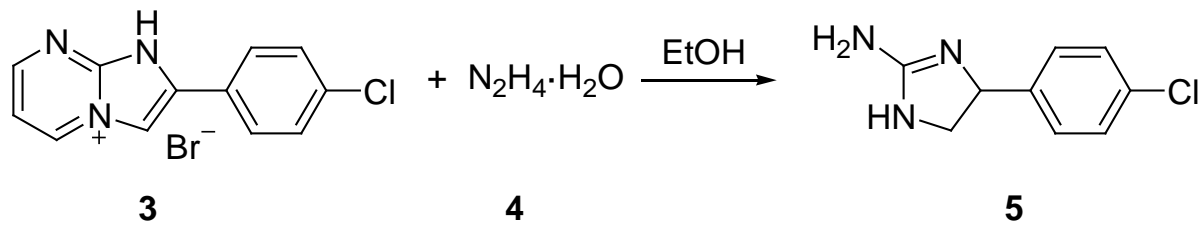

Scheme 3. Synthesis of 4-(4-chlorophenyl)-4,5-dihydro- $1 H$-imidazol-2-amine.

\subsection{Functionalisation of the surface of the alloy}

Several disks of Ti6Al4V alloy were mechanically polished to a mirror finish. These disks were successively cleaned with water, acetone and ethanol in an ultrasonic bath and dried prior to the passivation treatment. Passivation of the disks was achieve by immersion in a piranha solution followed by sonication, first in water, and then in ethanol.

The passivated disks were subjected to silanisation following protocols reported elsewhere (Rodríguez-Cano et al., 2013). Two different functional groups were used, (a) 3aminopropyltrimethoxysilane (AS) and (b) 3-methacryloxypropyltrimethoxysilane (MS). In both cases, the disks were immersed in $1 \mathrm{M}$ solution of the corresponding silane in toluene, stirred at $65{ }^{\circ} \mathrm{C}$ for several hours to form Ti-O-Si bonds, then rinsed in toluene and sonicated twice in the same solvent, and finally dried under air. The resulting silanised disks were heated in an oven at $120^{\circ} \mathrm{C}$ for $48 \mathrm{~h}$, so that lateral crosslinked chains form through the formation of Si-O-Si bonds. Finally, they were sonicated with $10 \mathrm{~mL}$ of toluene, water, acetone, and ethanol, successively, during 10 min each time.

According to ninhydrin tests and UV quantification, the concentration of free $-\mathrm{NH}_{2}$ groups on the amino-silanised Ti6Al4V surface is $1.69 \cdot 10^{-7} \mathrm{~mol} / \mathrm{cm}^{2}$. This result is slightly higher than that reported by a previous study,in which concentration of $3.3 \cdot 10^{-8} \mathrm{~mol} / \mathrm{cm}^{2}$ was measured (Rodríguez-Cano et al., 2013). The longer amino-silanisation time in this work could explain this difference.

X-Ray Photoelectron Spectroscopy was recorded for each disk in order to investigate the surface chemistry of the treated disks. Table 1 shows the percentages and ratios of $\mathrm{O}, \mathrm{C}, \mathrm{N}$, and Si on the surface of the silanised disks.

In the final step, non-covalent immobilization of 2-aminoimidazole (5) on the silanised surface of Ti6Al4V alloy was achieved by incubating each disk in a $1 \mathrm{M}$ solution of 5 in $10 \mathrm{~mL}$ ethanol at $50{ }^{\circ} \mathrm{C}$ for $24 \mathrm{~h}$. After that, they were sonicated twice with ethanol and dried under vacuum. The alloys coated with the aminoimidazole 5 (AI) were termed Ti6Al4V-AS-AI and Ti6Al4VMS-AI, according with the type of silanisation, with AS or MS, respectively. 
Table 1. Percentages and ratios of O, C, N and Si of silanised Ti6Al4V surfaces

\begin{tabular}{cccccccc}
\hline Sample & $\mathrm{O}$ & $\mathrm{C}$ & $\mathrm{N}$ & $\mathrm{Si}$ & $\mathrm{O} / \mathrm{Si}$ & $\mathrm{C} / \mathrm{Si}$ & $\mathrm{N} / \mathrm{Si}$ \\
\hline Ti6Al4V-AS $^{1}$ & $19.9 \pm 0.2$ & $61.9 \pm 0.4$ & $6.2 \pm 0.2$ & $11.5 \pm 0.1$ & $1.7 \pm 0.1$ & $5.4 \pm 0.2$ & $0.5 \pm 0.1$ \\
\hline Ti6Al4V-MS $^{2}$ & $40.2 \pm 1.3$ & $40.5 \pm 1.3$ & $3.1 \pm 0.3$ & $8.2 \pm 0.3$ & $4.9 \pm 0.9$ & $4.9 \pm 0.1$ & $0.4 \pm 0.1$ \\
\hline Ti6Al4V-AS-AI & $34.9 \pm 0.8$ & $45.3 \pm 0.7$ & $4.3 \pm 0.1$ & $6.2 \pm 0.2$ & $5.7 \pm 0.5$ & $7.3 \pm 0.5$ & $0.7 \pm 0.2$ \\
\hline Ti6Al4V-MS-AI $^{4}$ & $16.2 \pm 6.1$ & $68.5 \pm 11.4$ & $5.2 \pm 0.3$ & $9.3 \pm 3.3$ & $1.7 \pm 2.8$ & $7.4 \pm 8.1$ & $0.6 \pm 1.3$ \\
\hline Alloy: ${ }^{1}$ Silanised with AS. ${ }^{2}$ Silanised with MS. ${ }^{3}$ Silanised with AS and coated with Al. ${ }^{4}$ Silanised with MS and coated with AI.
\end{tabular}

The above data show that both silanised surfaces, Ti6Al4V-AS and Ti6Al4V-MS, are mainly composed of $\mathrm{C}$ and $\mathrm{O}$, which is in agreement with the formation of polysiloxane coatings. The $\mathrm{C} / \mathrm{Si}$ ratio on the Ti6Al4V-AS surface is slightly higher than that on Ti6Al4V-MS; this can be due to a thicker coating formed when AS is used. It is interesting to highlight, however, the low $\mathrm{N} / \mathrm{Si}$ ratio on these surfaces, which is less than 1.0. A side reaction based on the formation of tertiary amines via Si-N bonds followed by a Cope elimination have been suggested in order to explain such low N/Si ratio (Rodríguez Cano et al., 2013).

Regarding surfaces treated with 2-aminoimidazole, both surfaces have $\mathrm{C} / \mathrm{Si}$ and N/Si ratios higher than the corresponding silanised surfaces do. Thus, the amino-silanised surface evaluated has an average $\mathrm{C} / \mathrm{Si}$ ratio of 7.3, which means that there is an effective incorporation of 1.9 units of carbon per surface of siloxane chain. In a similar way, there is an incorporation of 2.5 units of carbon per surface on the MS functionalised surface. This difference seems logical, considering intermolecular forces between terminal amines or carbonyl groups and functionalities in 2aminoimidazole. Moreover, the $\mathrm{O} / \mathrm{Si}$ ratio on the Ti6Al4V-MS surface decreases after the treatment with AI. This is in agreement with the immobilisation of the nitrogenated heterocycle on the polysiloxane coating, which may mask oxygen atoms in methacrylate group.

High resolution XPS spectra of detected C(1s), O(1s), N(1s) are summarized in Figures 1, 2 and 3. XPS for C(1s) shows peaks for C-C (284.5 eV) and C-N (285.5 eV) bonds in every sample. Additionally, C(1s) spectra of Ti6Al4V-MS shows a peak for C=O bond (287.6 eV). In XPS spectra of $\mathrm{O}(1 \mathrm{~s})$ in Ti6Al4V-MS four peaks are observed, at 529.8, 531.0, 532.0 and $532.9 \mathrm{eV}$ for Ti-O, Si-O, C=O and C-O respectively. After 2-aminoimidazole linkage only two peaks are observed at $531.5(\mathrm{Si}-\mathrm{O})$ and $532.5(\mathrm{C}=\mathrm{O}) \mathrm{eV}$. The fit for $\mathrm{N}(1 \mathrm{~s})$ reveals the presence of free $\mathrm{NH}_{2}$ groups (399.5 eV) corresponding to the organosilane bound to Ti-surfaces.

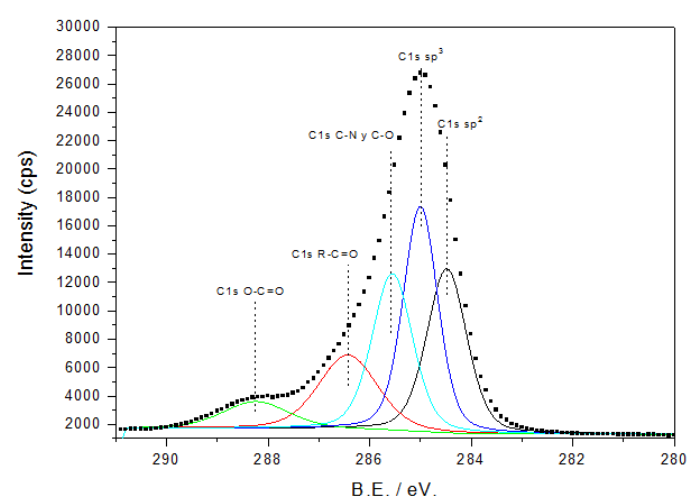

(a) Ti6Al4V-AS

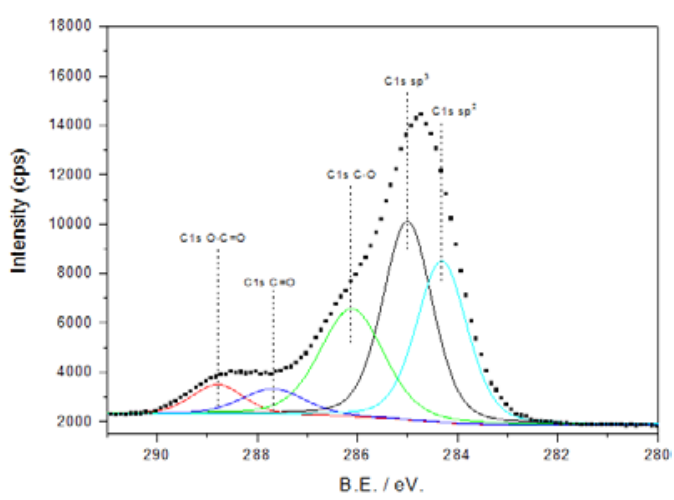

(b) Ti6Al4V-MS 


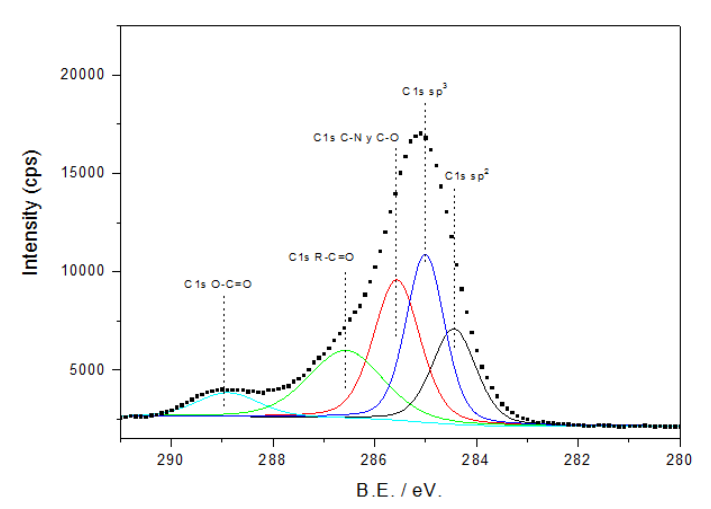

(c) Ti6Al4V-AS-AI

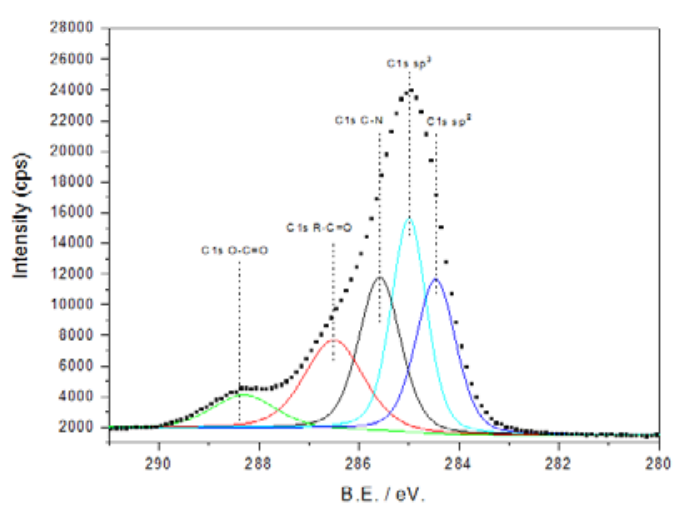

(d)

Figure 1. High-resolution XPS spectra and deconvolution of the C(1s) peak for (a) Ti6Al4V-AS, (b) Ti6Al4V-MS, (c) Ti6Al4V-AS-AI, and (d) Ti6Al4V-MS-AI.

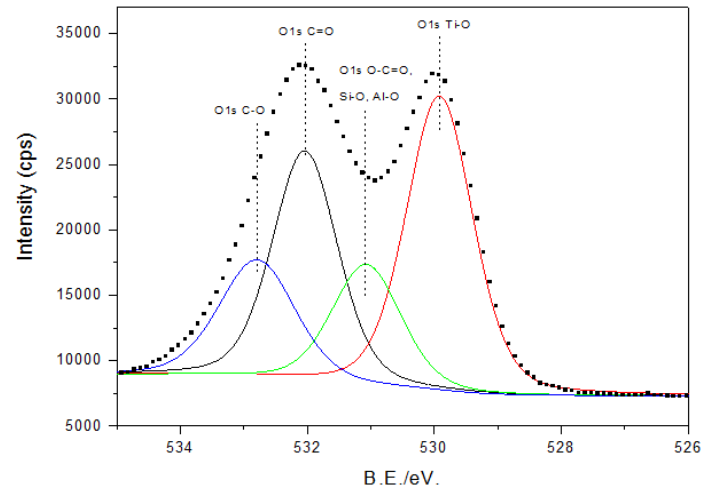

(a) Ti6Al4V-MS

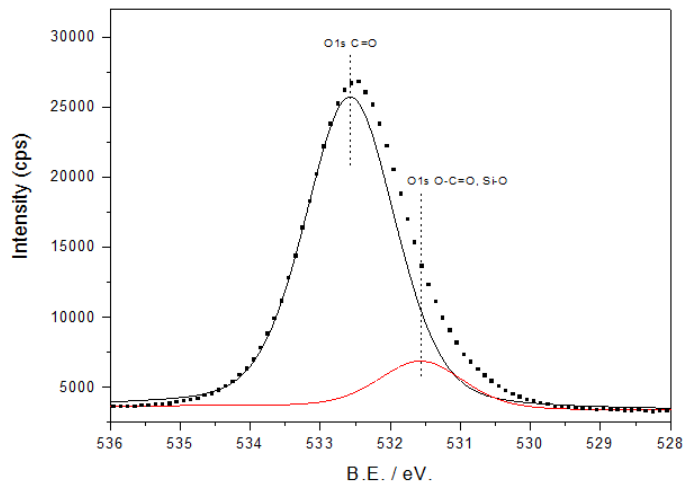

(b) Ti6Al4V-MS-AI

Figure 2. High-resolution XPs spectrum and deconvolution of the O(1s) peak for (a) Ti6AlVMS, and (b) Ti6Al4V-MS-AI.

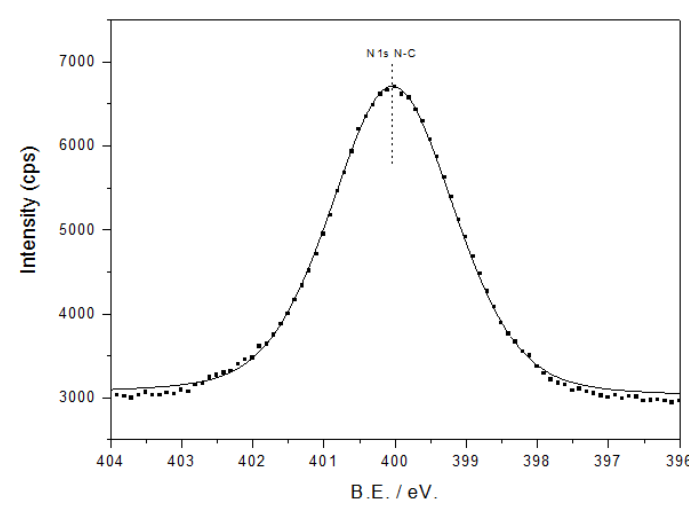

(a) Ti6Al4V-AS

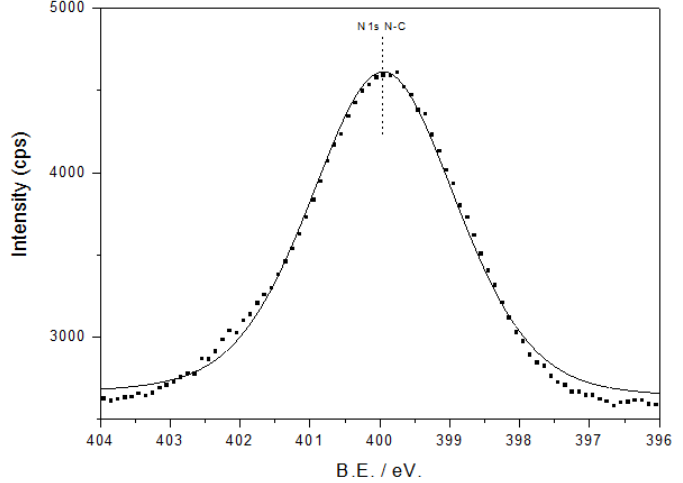

(b) Ti6Al4V-AS-AI 


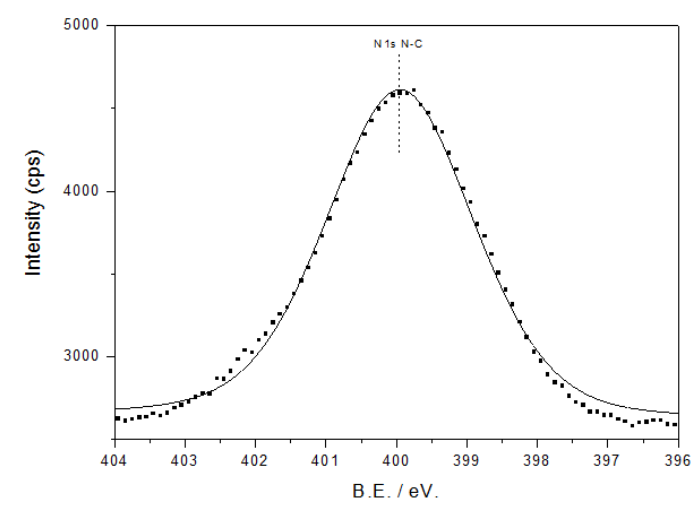

(c)

Figure 3. High-resolution XPs spectrum and deconvolution of the N(1s) peak for (a) Ti6AlVAS, (b) Ti6Al4V-AS-AI, and (c) Ti6Al4V-MS-AI.

\section{Conclusions}

The target 2-aminoimidazole (5), can be synthesised in two steps. In the first step an intermediate salt (3) is formed by the cyclocondensation of 2-bromo-1-(4chlorophenyl)ethanone (1) with 2-aminopyrimidine (2); and in the second step, hydrazinolysis of the intermediate salt yields the desired product, 4-(4-chlorophenyl)-4,5-dihydro-1H-imidazol2-amine (5).

3-(Aminopropyl)trimethoxysilane and 3-(methacryloxypropyl)trimethoxysilane polymer films can be covalently attached to the surface of Ti6Al4V through a silanisation process in toluene at $65^{\circ} \mathrm{C}$ to form Ti-O-Si bonds, followed by a curing process at $120^{\circ} \mathrm{C}$ in which lateral crosslinked chains form through the formation of Si-O-Si bonds.

The silanised surfaces of the alloy, either with 3-(aminopropyl)trimethoxysilane or with 3(methacryloxypropyl)trimethoxysilane, allow noncovalent attachment of 2-aminoimidazole. According to the results of the XPS spectroscopy, this union might be more important in the case of (methacryloxypropyl)trimethoxysilane.

\section{Experimental methodologies}

\subsection{Materials and methods}

Chemicals were obtained from Across, Aldrich Chemical Co., and Fluka and used without further purification. Analytical TLC was performed on silica gel Polygram Sil G/UV254 (0.25 $\mathrm{mm}$ ) from Aldrich, using visualization with UV light. Column chromatography was carried out on silica gel Merck 60 (particle size 230-400 mesh). Ti6Al4V disks (ELI grade 23), $25 \mathrm{~mm}$ in diameter and $2 \mathrm{~mm}$ in thickness were obtained from William Gregor Ltd. (UK) and DKSH Ltd. (SWZ). All aqueous protocols were performed with in-house distilled water or deionized water from a Milli-Q Plus system. Microwave-assisted reactions were performed using a CEM Discover microwave reactor (CEM Corp.) at 300W. Melting points were determined by a Barnstead Electrothermal IA9100 apparatus and are uncorrected. ${ }^{1} \mathrm{H}$ NMR and ${ }^{13} \mathrm{C}$ NMR spectra were recorded at 500 and $100 \mathrm{MHz}$, respectively, on a Bruker AVANCED spectrometer in DMSO- $d_{6}, \mathrm{MeOH}-d_{4}$ or $\mathrm{CDCl}_{3}$ as solvents, with TMS as the internal standard. IR spectra were recorded on a Thermo Electron Corporation IR300 FT-IR spectrometer. X-Ray Photoelectron Spectroscopy (XPS) was recorded in a Thermo Scientific spectrophotometer (Ka system) with 
monochromatised AlK $\alpha$ radiation at $12 \mathrm{kV}$. Measurements were taken at a take-off angle of $90^{\circ}$ with respect to the sample surface. The analysed area is typically $0.16 \mathrm{~mm}^{2}$. High-resolution XPS data were obtained for $\mathrm{N}(1 \mathrm{~s}), \mathrm{O}(1 \mathrm{~s})$ and $\mathrm{C}(1 \mathrm{~s})$ atoms. Background subtraction, peak integration and fitting were carried out with Advantage 1 software.

\subsection{Synthetic procedures}

- Synthesis of 2-(4-Chlorophenyl)-1H-imidazo[1,2-a]pyrimidin-4-ylium bromide (3)

2-bromo-1-(4-chlorophenyl)ethanone (1) (957 mg, $4.10 \mathrm{mmol}$ ) with 2-aminopyrimidine (2) (324 mg, $3.41 \mathrm{mmol})$ in acetonitrile $(15 \mathrm{~mL})$ 4-dimethylaminopyridine $(4.2 \mathrm{mg}, 0.034 \mathrm{mmol})$ was added. After heating under reflux for $5 \mathrm{~h}$, the reaction mixture was filtered, washed with acetonitrile $(10 \mathrm{~mL})$ and ether $(2 \times 10 \mathrm{~mL})$, and dried to give 3 as a white solid. Yield, $62 \%$; m.p. (219.5 $\left.{ }^{\circ} \mathrm{C}\right)$; IR (KBr) $v_{\max }\left(\mathrm{cm}^{-1}\right)$ : 3479, 3419, 3182, 3081, 3053, 2970, 2937, 2835, 2798, 2677, 2643, 1977, 1924, 1642, 1528, 1489, 1335, 1307, 1252, 1129, 1094, 928, 900. 803, 763, 732; ${ }^{1} \mathrm{H}-\mathrm{RMN}(500 \mathrm{MHz}$, DMSO-d6) $\delta 7.57$ (dd, $J=6.62,4.41 \mathrm{~Hz}, 1 \mathrm{H}) 7.68$ (d, $J=10.0 \mathrm{~Hz}, 2 \mathrm{H}$ ) 8.04 (d, $J=10 \mathrm{~Hz}, 2 \mathrm{H}) 8.76$ (s, 1H) 8.96 (d, $J=5.0 \mathrm{~Hz}, 1 \mathrm{H}) 9.29$ (d, $J=5 \mathrm{~Hz}, 1 \mathrm{H}$ ).

- Synthesis of 4-(4-chlorophenyl)-4,5-dihydro- $1 H$-imidazol-2-amine (5)

To a suspension of $3(100 \mathrm{~g}, 0.304 \mathrm{mmol})$ in ethanol $(2 \mathrm{~mL})$ in a $10 \mathrm{~mL}$ glass vessel hydrazine hydrate was added $(0.109 \mathrm{~mL}, 35 \%$ hydrazine in solution, $2.12 \mathrm{mmol})$. The vessel was sealed, placed in a microwave reactor, and heated at $120^{\circ} \mathrm{C}$ for $40 \mathrm{~min}$ (maximum power $=50 \mathrm{~W}$, ramp time $=3 \mathrm{~min}$ ). The mixture was cooled to room temperature, the solvent evaporated and the residue was purified by flash column chromatography using dichloromethane:methanol (10:1) with $\mathrm{Et}_{3} \mathrm{~N}(3 \% \mathrm{v} / \mathrm{v})$ as an eluent, to afford 2-aminoimidazole 5 as a pale yellow solid (dichloromethane:methanol:diethyl ether. Yield, $42 \%$; m.p. $\left(149.5{ }^{\circ} \mathrm{C}\right)$; IR $(\mathrm{KBr}) v_{\max }\left(\mathrm{cm}^{-1}\right)$ : 3347, 3105, 2913, 2720, 1895, 1679, 1632, 1544, 1491, 1351, 1241, 1165, 1137, 1095, 1032, 827, 778, 703; ${ }^{1} \mathrm{H}-\mathrm{RMN}\left(500 \mathrm{MHz}, \mathrm{CD}_{3} \mathrm{OD}-d 4\right) \delta 6,93(\mathrm{~s}, \mathrm{H} 5,1 \mathrm{H}), 7.29(\mathrm{~d}, J=10.0 \mathrm{~Hz}, 2 \mathrm{H})$ $7.53(\mathrm{~d}, J=10 \mathrm{~Hz}, 2 \mathrm{H}) ;{ }^{13} \mathrm{C}$ NMR $(100 \mathrm{MHz}) \delta 112.5,126.3,129.4,132.5,133.6,134.54$, 151.99 .

\subsection{Cleaning and amino-silanisation protocols for Ti6Al4V}

(a) Mechanical treatments

Ti6Al4V disks were mechanically polished to a mirror finish by using SiC grinding (Buehler P320, 300 rpm, 2 min), Ultrapad (9 nm, 150 rpm, MetaDi Fluid, 10 min) and Microcloth (150 rpm, MasterMet2, $10 \mathrm{~min}$ ). The polished disks were then cleaned in an ultrasonic bath with water, acetone and ethanol (10 min each, $30 \mathrm{~mL} \cdot$ disk $\left.^{-1}\right)$, dried at $40{ }^{\circ} \mathrm{C}$ for $30 \mathrm{~min}$ and stored under vacuum for $12 \mathrm{~h}$.

\section{(b) Chemical Oxidation}

Polished disks were immersed in a piranha solution generated from $98 \% \mathrm{H}_{2} \mathrm{SO}_{4}$ and $30 \%$ aqueous $\mathrm{H}_{2} \mathrm{O}_{2}\left(1: 1, \mathrm{v} / \mathrm{v}, 10 \mathrm{~mL} \cdot \operatorname{disk}^{-1}\right)$ at $45{ }^{\circ} \mathrm{C}$ for $30 \mathrm{~min}$. The activated disks were then sonicated $\left(30 \mathrm{~mL} \cdot \operatorname{disk}^{-1}\right)$ in water $(30 \mathrm{~min})$ and ethanol $(10 \mathrm{~min})$, and dried under a stream of hot air.

(c) Silanisation with 3-(aminopropyl)trimethoxysilane (AS) or 3-(trimethoxysilyl)propyl methacrylate (MS)

Ti6Al4V disks, previously subjected to a cleaning and passivation process, were immersed in a $1 \mathrm{M}$ solution of AS or MS in toluene $\left(10 \mathrm{~mL} \cdot \mathrm{disk}^{-1}\right)$. The reaction mixture was kept closed and heated at $65{ }^{\circ} \mathrm{C}$, with stirring at $50 \mathrm{rpm}$ for $18 \mathrm{~h}$. Disks were rinsed under flowing toluene, then sonicated twice in the same solvent $\left(30 \mathrm{~mL} \cdot\right.$ disk $\left.^{-1}\right)$ for $10 \mathrm{~min}$ each, and dried under air. The ultrasonic treatment was repeated twice. The resulting silanised disks were cured by heating in 
an oven at $120{ }^{\circ} \mathrm{C}$ for $48 \mathrm{~h}$. Then they were consecutively sonicated with toluene, water, acetone and ethanol (10 min each, $30 \mathrm{~mL} \cdot$ disk $\left.^{-1}\right)$.

(d) Ninhydrin assays

Disks subjected to the above-mentioned silanisation protocol were immersed in a suspension containing $\mathrm{SnCl}_{2}(0.35 \mathrm{mM})$, sodium citrate $(0.1 \mathrm{M}, \mathrm{pH}=5,1 \mathrm{~mL})$ and ninhydrin $(4 \%$ in $\mathrm{EtOH}$ $\mathrm{w} / \mathrm{v}, 1 \mathrm{~mL}$ ). The mixture was heated at $100{ }^{\circ} \mathrm{C}$ for $15 \mathrm{~min}$. The solution was cooled for $2 \mathrm{~min}$, then it was diluted with $\mathrm{EtOH} / \mathrm{H}_{2} \mathrm{O}(3: 2 \mathrm{v} / \mathrm{v}, 5 \mathrm{~mL})$ and amines were quantified by the measurement of absorbance $\mathrm{A}_{570}$ using a UV/vis spectrophotometer. The analysis was carried out in duplicate (Binoy et al., 2005).

\subsection{Non-covalent immobilization of 5 on the silanised surface of Ti6Al4V alloy}

Silanised Ti6Al4V disks were incubated in a $1 \mathrm{M}$ solution of 4-(4-chlorophenyl)-4,5-dihydro$1 \mathrm{H}$-imidazol-2-amine in ethanol $\left(10 \mathrm{~mL} \cdot \operatorname{disk}^{-1}\right)$ at $50{ }^{\circ} \mathrm{C}$ for $24 \mathrm{~h}$. After that, they were sonicated twice with ethanol $\left(10 \mathrm{~mL} \cdot\right.$ disk $\left.^{-1}\right)$ and dried under vacuum.

Acknowledgements The authors thank the Microbial Adhesion (AM-UEx) and the Organic Chemistry (QUOREX) Research Groups for their contributions to this project. Financial support was provided by the Department of Organic and Inorganic Chemistry of the University of Extremadura.

\section{References}

Ando, N., Terashima, S. (2010). A novel synthesis of the 2-amino- $1 H$-imidazol-4carbaldehyde derivatives and its application to the efficient synthesis of 2-aminoimidazole alkaloids, oroidin, hymenidin, dispacamide, monobromodispacamide, and ageladine A. Tetrahedron, 66, 6224-6237.

Ang, G., Ruiqiang, H., Chu, P. (2016). Recent advances in anti-infection surfaces fabricated on biomedical implants by plasma-based technology. Surf. Coat. Tech., 1-5.

Binoy, J., Antoci Jr, V., Allen, R., Wickstrom, E., Hickok, N. (2005). Vancomycin Covalently Bonded to Titanium Beads Kills Staphylococcus aureus. Cell Chemical Biology, 12(9), 1041-1048.

Fung, S.-Y., Sofiyev, V., Schneiderman, J., Hirschfeld, A., Victor, R., Woods, K., de Voogd, N. (2014) Unbiased screening of marine sponge extracts for anti-inflammatory agent combined with chemical genomics identifies girolline as an inhibitor of protein synthesis. ACS Chem. Biol, 9(1), 247-257.

Mai, T., Tintillier, F., Lucasson, A., Moriou, C., Bonno, E., Petek, S., Magré, K., Al-Mourabit, A., Saulnier, D., Debitus, C. (2015) Quorum sensing inhibitors from Leucetta chagosensis Dendy, 1863. Lett. Appl. Microbiol., 61(4), 311-317.

Rautray, T., Narayanan, R., Kwon, T.-Y., Kim, K.-H. (2010) Review Surface Modification of Titanium and Titanium Alloys by Ion Implantation. J. Biomed. Mater. Res. B Appl. Biomater., 93(2), 581-591.

Rodríguez-Cano, A., Cintas, P., Fernández-Calderón, M.-C., Pacha-Olivenza, M.-Á., Crespo, L., Saldaña, L. Babiano. R. (2013) Controlled silanization-amination reactions on the Ti6Al4V surface for biomedical applications. Colloids and Surfaces B: Biointerfaces, 106, 248-257.

Žula, A., Kikelj, D., Ilaš, J. (2015) Chemistry of 2-Aminoimidazoles. J. Heterocyclic Chem., 111. 